\title{
Titik Temu Mistisisme Islam dan Mistisisme Jawa; Studi Analitis terhadap Persinggungan Ajaran Tasawuf dan Kejawen
}

\author{
Ahmad Yuzki Faridian Nawafi ${ }^{1}$ \\ ${ }^{1}$ Institut Agama Islam Negeri (IAIN) Tulungagung \\ 1yuzkimaksum1@gmail.com
}

\begin{abstract}
This article discusses the mysticism contained in Islam and Javanese culture. Islamic mysticism is known as sufism while Javanese mysticism is known as kebatinan. Although the teachings of sufism originate from normative islamic values that come from the Qur'an and hadith, while kebatinan is born from the crystallization of local Javanese beliefs and culture, both of them have common ground in terms of goals, namely to make adherents into perfect human beings through intermediary union of a being with the Creator (Khaliq). In this article, the descriptive-analytic method is used to critically explain sufism and kejawen and how they are related in the context of mysticism. This study concluded that the teachings of sufism and kejawen have several similarities in terms of objectives, namely; unite with God as an effort to become a perfect human. Then both have other similarities in terms of processes or efforts to achieve these goals through distribution, concentration, and representation. In addition, they both indicate the urgency of a guide in carrying out the mystical process.
\end{abstract}

Key Word: Kebatinan., Mystical, Sufism.

\begin{abstract}
Abstrak
Artikel ini membahas tentang mistisisme yang terdapat dalam Islam dan kebudayaan Jawa. Mistik Islam dikenal dengan tasawuf sedangkan mistik Jawa dikenal dengan aliran kebatinan. Meskipun ajaran tasawuf berasal dari nilai-nilai Islam normatif yang bersumber dari Al-Qur'an dan hadis, sedangkan aliran kebatinan lahir dari kristalisasi kepercayaan dan budaya lokal Jawa, namun keduanya memiliki titik temu dari segi tujuan, yakni menjadikan penganutnya sebagai manusia yang sempurna melalui perantara penyatuan diri seorang makhluk dengan Sang Pencipta (Khaliq). Pada artikel ini digunakan metode deskriptif-analitik untuk menjelaskan secara kritis mengenai tasawuf dan kejawen serta bagaimana relasi keduanya dalam konteks mistisisme. Penelitian ini menyimpulkan bahwa ajaran tasawuf dan kejawen memiliki beberapa persamaan dalam hal tujuan, yakni; bersatu dengan Tuhan sebagai upaya menjadi manusia yang sempurna. Kemudian keduanya memiliki kesamaan lain dari segi proses atau usaha untuk mencapai tujuan tersebut melalui distansi, konsentrasi, dan representasi. Selain itu, keduanya sama-sama mengindikasikan urgensi seorang pembimbing dalam melakukan proses mistik.
\end{abstract}

Kata Kunci: Kebatinan, Mistik, Tasawuf. 


\section{Pendahuluan}

Manusia pada dasarnya adalah makhluk yang memiliki kepercayaan yang tinggi terhadap sebuah kekuatan universal. Manusia selalu berusaha untuk mendekatkan diri kepada Tuhan, bahkan lebih lanjut manusia berupaya untuk manunggaling dengan Tuhan. Berusaha menghadirkan Tuhan sebagai cerminan kerinduan manusia akan Tuhannya. Sebagai sebuah manifestasi pemaknaan hidup yang berusaha untuk menjadi manusia yang sempurna atau insan kamil.

Usaha manusia untuk mendekatkan diri sedekat-dekatnya dengan Tuhan untuk mencapai kesempurnaan hidup lazim disebut dengan mistik. Mistisisme telah dikenal lama baik di Barat maupun Timur. Perjalanan spiritual ini juga dimiliki oleh agama-agama lain di dunia seperti Hindu, Budha, Kristen, Yahudi dan Islam. Sedangkan banyak juga aliran atau pecahan agama di dunia ini yang juga mengembangkan konsep perjalanan batin spiritual seperti ini. Dalam Islam proses perjalanan mistik ini disebut dengan tasawuf atau sufisme yang biasanya dilakukan dalam sebuah aliran tarekat. ${ }^{1}$ Sedangkan mistik yang bersumber kepada budaya spiritual yang dalam hal ini budaya Jawa disebut

1 Harun Nasution, Filsafat Dan Mistisisme (Jakarta: Bulan Bintang, 1978), 50. dengan mistik kejawen yang biasanya dipelajari dalam aliran kebatinan. ${ }^{2}$

Islam sebagai agama yang lahir di jazirah Arab merupakan agama yang berlandaskan al-Quran sebagai kitab suci. Serta ucapan, tindakan dan ketetapan Muhammad sebagai Rasul-Nya yang biasa disebut dengan as-Sunnah. Setelah wafatnya Muhammad SAW, Islam banyak bersinggungan dengan faham ajaran lain seperti pemikiran Yunani, Persia bahkan India. Persinggungan ini kemudian membawa hal-hal baru ke dalam tubuh agama Islam. Agama Islam kemudian bergabung dengan budaya lokal agar lebih mudah agama ini diterima. Namun tetap berfondasi kepada al-Quran dan as-Sunnah.

Jawa merupakan sebuah peradaban lama yang telah dikenal di Indonesia. Kebudayaan Jawa banyak bersinggungan dengan ajaran agama yang sebelumnya telah berada di Jawa seperti Hindu, Budha, Kristen dan juga Islam. Budaya lokal Jawa membaur dengan kebudayaan luar yang datang ke nusantara. Pada saat Islam datang ke Jawa terjadi penggabungan unsur Islam dengan kebudayaan lokal di Jawa yang pada saat itu masih menganut Hindu Budha.

Islam datang ke nusantara salah satunya dengan membawa ajaran mistik.

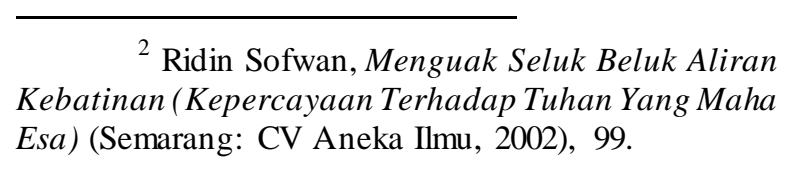


Ajaran ini menekankan pada proses menyebarkan ajaran Islam melalui penyatuan manusia dengan Tuhan yang pendekatan kultural. $^{3}$

banyak dikisahkan sebagai ajaran yang Indonesia sebagai Negara dengan dibawa oleh Syekh Siti Jenar. Bagi penganut agama Islam terbesar di dunia serta masyarakat Jawa, proses penyatuan hamba terdapat pula ajaran mistik yang bersumber dengan Tuhan telah dikenal jauh sebelum dari budaya lokal seperti Jawa, sehingga Islam hadir di bumi nusantara, sehingga dirasa perlu untuk memahami kedua konsep ajaran mistik Islam dan kejawen mengalami ini agar terjadi sikap saling hormat persinggungan langsung dan dinamika yang menghormati antara pemeluk. Pada dasarnya kompleks. Kedua ajaran ini kemudian saling konsep mistisisme yang terdapat dalam Islam melengkapi antara satu dengan yang lain dan kejawen memiliki beberapa kesamaan seperti peristiwa pada masa Jaka Tingkir yang mana keduanya mengajarkan bahwa pemimpin kerajaan Pajang. Ia dikenal setiap manusia berasal dari-Nya dan akan sebagai pemegang kekuasaan Islam dan juga kembali kepadanya atau dalam istilah Jawa penganut kejawen.

Dalam sejarah perkembangan Islam dikenal dengan konsep sangkan paraning dumadi. Sehingga perlu untuk menjelaskan di Indonesia, terdapat aliran Islam kejawen. Aliran ini adalah bentuk adaptasi dari agama Islam dengan budaya lokal Jawa yang beberapa konsep mistisime di antara keduanya yang bisa dijadikan titik temu antara tasawuf dan kebatinan.

kemudian menciptakan sebuah identitas religusitas unik, yakni Islam dalam wajah Jawa (akulturasi). Dengan kata lain, Islam

\section{Metode Penelitian}

Penelitian ini merupakan penelitian kejawen merupakan wujud peleburan nilai- library research, yaitu penelitian yang nilai ajaran Islam dengan sosio-kultural lokal memperoleh data dengan menggunakan masyarakat Jawa, khususnya berkaitan literatur pustaka didasarkan pada data tertulis dengan aspek-aspek mistisisme. Bahkan, yang berbentuk jurnal, buku, artikel yang Islam kejawen secara sosio-kultural adalah sesuai dengan objek tema yang dikaji. merupakan sub-kultur dan bagian dari Adapun sifat penelitian ini adalah bersifat budaya Jawa. Ini terjadi karena pada masa deskriptif-kualitatif, yaitu berdasar pada kerajaan Demak dan sesudahnya, para Wali kualitas data yang telah diuraikan dan dalam Kesejarahan Kultur Lokal)," IAIN Surakarta, last modified February 24, 2016, accessed August 17, 2020 https://iain-surakarta.ac.id/is lam-kejawenagama-dalam-kesejarahan-kultur-lokal/. 
dianalisis secara sistematis dan bertujuan untuk mendeskripsikan dan menganalisis fenomena atau peristiwa tertentu yang terjadi di sekitar manusia. ${ }^{4}$

Sumber data penelitian ini adalah buku-buku, kitab, jurnal dan tulisan-tulisan ilmiah terkait mistisme Islam dan mistisme Jawa sebagai data primer. Kemudian data sekunder, yaitu literatur-literatur lainnya yang tidak terkait dengan mistisme Islam dan mistisme Jawa namun dapat dijadikan sebagai data pendukung penelitian seperti referensi tentang metodologi. Adapun objek kajian dalam penelitian ini adalah mistisme Islam dan mistisme Jawa sebagai objek formal dan titik temu antara kedua ajaran tersebut sebagai objek material.

Secara umum, penelitian ini memiliki 2 tahapan, yaitu: pengumpulan data, analisis dan pemaparan data. Data diperoleh melalui 2 metode, yakni observasi dan dokumentasi. Pada proses observasi digunakan metode pencarian manual tentang pembahasan terkait mistisme Islam dan mistisme Jawa dalam berbagai literatur keislaman dan keindonesiaan, khususnya mengenai tasawuf dan kejawen. Selanjutnya data didokumentasikan dengan cara mengorganisasikan data ke dalam kategori tertentu, menjabarkan ke dalam setiap unitnya, menyortir data dan membuat

4 Nana Syaodih Sukmadinata, Metode Penelitian Pendidikan (Bandung: Remaja Rosdakarya, 2010), 60 . Jurnal Intelektual: Jurnal Pendidikan dan Studi Keislaman Volume 10, Nomor 2, Agustus 2020 kesimpulan agar dapat dipahami dengan mudah oleh pembaca. ${ }^{5}$

Setelah data terkumpul, hal tersebut kemudian dianalisis menggunakan metode deskriptif-analitik yaitu metode analisis dengan cara memaparkan permasalahan dengan analisis serta memberikan penjelasan secara mendalam terkait sebuah data. Sehingga penelitian tidak hanya sebatas pada pengumpulan data, namun meliputi analisis dan interpretasi data. ${ }^{6}$ Setelah itu digunakan metode analisis-komparatif untuk melihat secara lebih jelas persamaan ajaran tasawuf dan kejawen.

\section{Hasil dan Pembahasan}

\section{Hakikat dan Sejarah Mistisisme Islam}

Islam merupakan agama yang ajaranajarannya diwahyukan Tuhan kepada manusia melalui Nabi Muhammad SAW. Bagi pemeluk agama Islam, tujuan hidup manusia bukan hanya mencari keselamatan dunia tetapi juga keselamatan akhirat. Rasulullah sebagai Rasul juga melakukan olah jiwa atau pengalaman spiritual seperti ketika beliau isra mi'raj dan bertemu dengan Allah untuk mendapatkan perintah salat. Pengalaman Rasulullah ini merupakan sebuah kondisi spiritual puncak di kalangan \begin{tabular}{l}
\hline 5 Sugiyono, Metode Penelitian Pendidikan \\
(Pendekatan Kualitatif, Kuantitatif Dan R\&D) \\
(Bandung: CV Alfabeta, 2010), 396. \\
Winarno Surakhmad, Pengantar Penelitian \\
Ilmiah Dasar, Metode Dan Teknik (Bandung: \\
Transito, 1980), 45.
\end{tabular} 
kaum sufi. Pada zaman sahabat terdapat sufi. ${ }^{10}$ Dalam tradisinya para kaum sufi ini kelompok yang tertarik terhadap hal-hal yang memiliki jalan atau metode untuk bersifat batiniah, mereka disebut dengan ahl- mendekatkan diri kepada Sang Pencipta yang shuffah yakni sejumlah sahabat yang hidup lazim disebut tarekat. Secara etimologi kata sebagai faqir dan setia kepada masjid. ${ }^{7}$

Menurut para pemikir muslim, ada “tarekat” berasal dari bahasa Arab طريقة yang merupakan bentuk mashdar (kata benda) dari tiga kategori ajaran dan ilmu pengetahuan yang satu sama lain saling berhubungan. Tiga kata tersebut yang memiliki arti الكيفية (jalan, kategori tersebut ialah fiqih (hukum), tauhid (teologi), dan tasawuf (mistisisme). Para pelaku tasawuf (sufi-sufi) seringkali cara), المذهب (metode, sistem), الأسلوب (madzhab, aliran), dan الحالة (keadaan). Secara istilah seperti yang diungkapkan Shihab pengertian tarekat adalah suatu jalan menekankan kesederhanaan hidup dengan menuju Tuhan (Allah) yang dapat menjauhkan diri dari kemewahan materi. membawanya kepada kebahagiaan dunia Mereka selalu berusaha mendekati Tuhan, akhirat. ${ }^{11}$

sehingga mereka merasakan cinta Tuhan dan Secara terminologi tasawuf adalah melihat Tuhan dengan mata hatinya. ${ }^{8}$ ilmu yang berorientasi untuk memperbaiki Sedangkan menurut Fadeli tasawuf hati dan membersihkan jiwa serta mengajarkan terhadap bentuk penyucian jiwa menfokuskannya hanya kepada Allah semata. sebuah proses terhadap makna tertinggi yakni kedekatan terhadap Tuhan dengan cara melakukan riyadhah atau usaha untuk mengosongkan hati dari selain Allah. ${ }^{9}$

Secara etimologi kata shufi (kaum sufi) berasal dari kata shuf (wol) yang digambarkan para sufi menggunakan kain wol untuk berpakaian sebagai implementasi kezuhudan mereka, sehingga muncullah sebutan tasawuf yang berarti ajaran kaum

\footnotetext{
7 Nurcholis Madjid, Islam Doktrin Dan Peradaban (Jakarta: Dian Rakyat, 2008), 225-256.

${ }^{8}$ Nasution, Filsafat Dan Mistisisme, 58.

9 Soeleiman Fadeli, Antologi NU: Sejarah, Istilah-Amaliyah-Uswah (Surabaya: Khalista, 2007),
} 152. Imam Zarkasyi Al-Anshari berkata: "tasawuf adalah ilmu untuk membersihkan jiwa, memperbaiki budi pekerti serta merekonstruksi lahir dan batin agar bisa memperoleh kebahagiaan yang abadi." ${ }^{, 12}$ Dengan demikian, tasawuf merupakan sebuah usaha dan upaya manusia untuk menyucikan diri dengan cara menjauhkan diri dari pengaruh duniawi yang dapat melalaikan mereka dan memusatkan jiwa dan raga hanya kepada Allah SWT melalui

10 Madjid, Islam Doktrin Dan Peradaban, 251.

11 Alwi Shihab, Antara Tasawuf Sunni Dan Tasawuf Falsafi Akar Tasawuf Di Indonesia (Depok: Pustaka Iman, 2009), 183.

12 Abdul Qadir Isa, Hakekat Tasawuf (Jakarta: Qisthi Press, 2005), 5. 
perenungan, dhikr dan ibadah sebagaimana yang telah dilakukan Rasulullah. ${ }^{13}$

Bentuk pengalaman

Rasulullah merupakan sebuah puncak keruhanian yang telah dicapai oleh seorang Nabi. Para sufi berusaha mencapai itu dengan skala, dimensi, dan format yang sepadan dengan kemampuan mereka. Hal ini dikarenakan inti dari pengalaman tersebut adalah penghayatan yang dalam akan situasi di mana diri bertemu dengan Dzat yang Maha Agung. ${ }^{14}$ Pertemuan dengan Tuhan akan membawa sebuah kebenaran sejati dan terbukanya hijab antara hamba dan Tuhan. Jalan ini membawa terhadap sebuah metode atau tarekat seperti Ibnu Farabi melakukan pengunduran diri atau khalwat dari dunia ramai.

Tujuan utama tasawuf adalah pengalaman dan kesadaran berhubungan dengan Tuhan secara langsung, berada sedekat-dekatnya dengan Tuhan secara sadar sehingga seseorang berada di hadirat Tuhan, Tuhan dihayati sebagai dzat yang hadir jelas di hadapan mata, atau kemudian para sufi dapat mampu merasakan cinta Tuhan dan dapat berhubungan mesra dengan Nya. ${ }^{15}$ Untuk menggapai tujuan ini para ahli tasawuf yang biasa dikenal dengan para sufi

\footnotetext{
13 Badrudin, Pengantar Ilmu Tasawuf (Serang: A-Empat, 2015), 1.

14 Madjid, Islam Doktrin Dan Peradaban, 257.

15 Mustafa Zahri, Kunci Memahami Ilmu Tasawuf (Surabaya: PT Bina Ilmu, 1979), 55. Jurnal Intelektual: Jurnal Pendidikan dan Studi Keislaman Volume 10, Nomor 2, Agustus 2020

16 Sofwan, Menguak Seluk Beluk Aliran Kebatinan (Kepercayaan Terhadap Tuhan Yang Maha Esa), 100.

17 Annemarie Schimmel, Dimensi Mistik dalam Islam (Jakarta: Penerbit Pustaka Firdaus, 1986), 3.
}

melakukan proses zuhud yakni berusaha hidup sederhana dan tidak menggantungkan kehidupan dengan dunia.

Para sufi juga menggunakan tasawuf sebagai sarana memperhalus sikap dan budi pekerti seseorang ketika hendak berhadapan dengan makhluk Tuhan dan lebih-lebih hubungan terhadap Tuhanya. Sikap ini bersifat moralistik yang berkembang pada aliran tasawuf awal. Kehalusan ini digunakan untuk memperhalus ajaran agama yang berada dalam kerangka syari'at yang dirasa terlalu kaku dan ketat dengan hukum-hukum salah dan benar. Tasawuf yang berguna untuk memperhalus budi ini disebut dengan tasawuf akhlaki atau tasawuf sunni ${ }^{16}$, lebih lanjut menurut Schimmel dapat disebut dengan mistik kepribadian (mysticism personality). ${ }^{17}$

Model tasawuf ini memahami bahwa manusia dan Tuhan merupakan realitas yang berbeda sehingga tidak muncul bentuk penyatuan antara Tuhan dan makhluk. Tasawuf ini lebih menekankan kepada ma'rifat billah memahami Allah. Bahwa manusia hidup berdasarkan kekuasaan Tuhan dan menerima segala apa yang diberikan Tuhan. Al-Ghazali mengungkapkan bahwa konsentrasi keseluruhan aktifitas hanya 
kepada Allah, hal ini membawa kepada kesatuan wujud yakni terpusatnya pandangan batin seseorang kepada Allah (wahdatul syuhud). ${ }^{18}$

Tasawuf yang selanjutnya adalah model tasawuf falsafi yakni konsep tasawuf yang menekankan kepada insan kamil atau manusia sempurna. Di sini dipahami bahwa manusia dan Tuhan memiliki esensi yang sama, sehingga untuk mencapai kesempurnaan manusia harus merealisasikan potensi ketuhanan yang ada dalam dirinya. Al-Farabi dengan konsep wahdatul wujud nya memandang bahwa alam semesta ini merupakan penampakan (tajalli) dari namanama dan sifat-sifat Tuhan, sehingga sebenarnya realitas alam semesta hanyalah satu, yakni Tuhan (realitas tunggal). ${ }^{19}$

Proses untuk mencapai manusia sempurna atau kesatuan tersebut diperoleh dengan usaha dan proses yang bisa disebut dengan riyadhah (melatih diri) dan mujahadah (berjuang), berjuang untuk melepaskan diri dari belenggu hawa nafsu dan sifat-sifat kemakhlukan yang merupakan penghalang (hijab) antara manusia sebagai makhluk dan Tuhan. Riyadhah yang biasa dilakukan oleh para sufi adalah dengan melakukan dhikr-dhikr atau ritual seperti Ulama Menyorot Tarikat Mistik (Kediri: Mitra Gayatri, 2004), 15.

19 Sofwan, Menguak Seluk Beluk Aliran Kebatinan (Kepercayaan Terhadap Tuhan Yang Maha Esa), 101. puasa, semedi, dan uzlah (pergi dari keramaian) untuk mengolah batin mereka. Dalam tasawuf banyak cara untuk menuju Tuhan salah satunya adalah dengan sistem pendidikan tiga tingkat yakni takhalli, tahalli, dan tajalli. ${ }^{20}$

Takhalli sebagai sistem pertama yang berarti mengosongkan diri dari sikap ketergantungan terhadap dunia. Pada proses ini manusia dituntut untuk menjauhi diri dari maksiat dan hawa nafsu seperti sombong, kikir, pemarah dan berbohong. Kemudian berlanjut kepada sistem yang kedua yakni tahalli yang berarti mengisi jiwa yang kosong tersebut dengan sifat yang terpuji seperti rendah hati, dermawan, sabar dan syukur. Setelah dua tingkatan ini dilewati maka selanjutnya seseorang akan masuk ke tingkatan tajalli yakni kondisi di mana seseorang telah memperoleh kesempurnaan jiwa dan terbukanya dinding antara makhluk dengan Tuhan. Proses ini menuntut adanya seorang guru atau mursyid agar tidak terjadi kesesatan untuk membimbing dan mengarahkan dalam proses riyadhah ini.

\section{Aliran Kebatinan Masyarakat Jawa}

Kebatinan merupakan bahasa Indonesia yang diserap dari bahasa Arab "batin" bermakna "di dalam" atau "tersembunyi". Secara istilah, kebatinan dapat dimaknai sebagai gerak badan rohani

${ }^{20}$ Nasution, Filsafat Dan Mistisisme, 56. 
atau olah batin. ${ }^{21}$ Sementara itu aliran keyakinan Islam dengan konsep-konsep kebatinan atau yang sekarang lebih dikenal Hindu Budha yang lebih condong kearah sebagai aliran kepercayaan adalah suatu mistik. $^{26}$

sistem kepercayaan atau spiritual yang ada di Indonesia selain agama, aliran, sekte, serta bukan pula termasuk dalam kepercayaan adat. $^{22}$ Aliran kebatinan sendiri memiliki definisi sebagai berikut "sumber azas dan sila ketuhanan yang maha esa untuk mencapai budi luhur, guna kesempurnaan hidup". Kesempurnaan hidup dan kebaikan budi pekerti ini diperoleh dari sebuah pemahaman falsafah Jawa yakni sepi ing pamreh rame ing gawe yang memiliki arti bahwa segala tindakan dan perbuatan manusia hendaknya didasari oleh rasa ikhlas. ${ }^{23}$

Aliran kebatinan banyak berkembang di Jawa karena hampir 45\% aliran kebatinan berada di Jawa terutama Jawa Tengah. ${ }^{24}$ Aliran kebatinan merupakan inti sari dari falsafah Jawa yang biasa disebut dengan "ngelmu kejawen". 25 Sedangkan ngelmu kejawen disebut oleh Kunjtaraningrat sebagai agama Jawi, yaitu warisan agama Islam yang dianut oleh orang Jawa yang bersifat sinkretis yang menyampuradukkan

21 Kiki Muhamad Hakiki, "Aliran Kebatinan Di Indonesia," Al-Adyan: Jurnal Studi Lintas Agama 6, no. 2 (December 31, 2011): 68-69.

22 Sofwan, Menguak Seluk Beluk Aliran Kebatinan (Kepercayaan Terhadap Tuhan Yang Maha Esa), 1

${ }^{23}$ Sofwan., 13

${ }^{24}$ Sofwan., 15.

25 Niels Mulder, Kepribadian Jawa Dan Pembangunan Nasional (Yogyakarta: Gajah Mada University Press, 1973), 14. Jurnal Intelektual: JurnalPendidikan dan StudiKeislaman Volume 10, Nomor 2, Agustus 2020
Kartapradja mengungkapkan bahwa kebatinan adalah suatu ilmu yang bersangkutan dengan ajaran-ajaran mistik. Ilmu kebatinan disebut juga dengan ilmu hakikat, ngelmu sejati, yaitu ilmu yang bertujuan untuk mencari hakikat hidup, hakikat manusia dan hakikat Tuhan. ${ }^{27}$ Aliran kebatinan bertujuan untuk mencapai kesempurnaan puncak seorang manusia dengan Tuhan-Nya yakni manusia telah manunggal atau bersatu dengan Tuhan yang tertuang dalam konsep manunggaling kawulo gusti. Pada tingkatan ini manusia telah merasakan keindahan surga dan merasa sangat dekat dengan Tuhan. Terbukanya hijab atau batas-batas dan biasa mendapat daya linuwih, sasmita, atau wahyu. ${ }^{28}$

Manunggaling kawulo gusti atau dalam istilah lain dikenal dengan jumbuhing kawulo gusti, sedangkan dalam aliran Sumarah dikenal dengan wor winoring loroloroning atunggal. Memiliki arti yang sama yakni suatu kondisi persatuan antara makhluk (kawula, hamba, manusia) dengan gusti (Tuhan), manusia sebagai makhluk melebur

26 Koentjaraningrat, Kebudayaan Jawa (Jakarta: Balai Pustaka, 1984), 311-312.

27 Kamil Kartapradja, Sejarah Klenik Dan Perkembangnya (Jakarta: Fakultas Ushuluddin IAIN Syarif Hidayatullah, 1972), 3.

28 Sofwan, Menguak Seluk Beluk Aliran Kebatinan (Kepercayaan Terhadap Tuhan Yang Maha Esa), 18 
dengan Tuhan menjadi satu dan dalam satu, seperti yang diungkapkan oleh Sosrosudigdo dalam istilah keris yang bersatu dengan kerangkanya (curiga manjing ing rangka, rangka manjing ing curiga). ${ }^{29}$ Bergabungnya diri dengan Tuhan ini akan dirasakan oleh orang yang ngelmu sebagai sebuah kondisi kosong tak sadarkan diri atau ekstase yang tidak dapat digambarkan dengan baik karena pengalaman ini bersifat subjektif.

Lebih lanjut Sofwan menjelaskan bahwa manusia di dunia ini tidaklah otonom manusia harus mampu menjadi bagian dari keseluruhan dan mampu menyatu dengan yang maha otonom. ${ }^{30}$ Upaya ini dilakukan manusia dengan cara beralih dari kedudukan seorang "kawula" menjadi bersatu dengan Gusti. Ajaran Hindu juga menjelaskan kondisi keberpindahan kedudukan ini seperti atman (manusia) bisa berubah kedudukan yang lebih tinggi menjadi paramatman yang identik dengan Brahman. Hal ini didapatkan ketika seseorang telah mencapai inti dirinya (purusha) maka ia akan merasa menyatu dengan Tuhan (isywara), dalam Islam dikenal dengan istilah man 'arofa nafsahu waman 'arofa rabbahu yang berarti 'Barangsiapa mengenal (mengetahui) dirinya

${ }^{29}$ Sawerdi Sosrosudigdo, Fungsi Dan Aliran Kebatinan Untuk Pribadi Dan Revolusi (Jakarta: Balai Pustaka, 1965), 9.

30 Sofwan, Menguak Seluk Beluk Aliran Kebatinan (Kepercayaan Terhadap Tuhan Yang Maha Esa), 46. maka ia akan mengenal (mengetahui)

Tuhannya.'

Pengalaman dan pengahayatan masyarakat Jawa akan istilah sangkan paraning dumadi membawa pada proses upaya untuk mendapatkan kehidupan yang baik dan menjadi manusia yang sempurna. Sangkan paraning dumadi sendiri memiliki arti asal dan kembalinya segala yang ada, di sini dapat diketahui ajaran-ajaran tentang Tuhan, manusia dengan alam, siapakah manusia dan apa tujuan manusia diciptakan. Konsep ini kemudian membawa aliran kebatinan kepada sebuah pemahaman bahwa manusia berasal dari Tuhan dan akan kembali kepada Tuhan. Sehingga aliran kebatinan kemudian memberikan jalan dan cara agar manusia siap kembali dan mampu memahami perannya sebagai makhluk hidup. ${ }^{31}$

Kunjaraningrat dalam buku Kebudayaan Jawa menjelaskan bahwa sejatinya manusia hidup di dunia hanya sebatas mampir ngombe (berhenti sebentar untuk minum) dalam menjalani kehidupan panjang yang bermuara pada bersatunya diri dengan Tuhan. Upaya untuk mencapai tujuan tersebut, manusia harus memiliki sikap rila (rela) dan narima (nerima). Rela adalah sikap yang mau dan mampu melepaskan diri dari kebendaan, melepaskan hak milik, pikiran perasaan untuk memiliki serta keinginan 
untuk dimiliki. Dengan sikap rela ini maka unsur rohani dalam diri akan muncul. Selanjutnya adalah sikap nerima, sikap ini sebenarnya merupakan sarana agar seseorang mampu untuk rela. Nerima adalah sikap menerima nasib dan bersabar atas segala yang diterima dan dikaruniakan Sang Pencipta kepadanya. Sikap ini diperoleh dari gaya hidup yang sederhana dan berupaya lain dengan cara melakukan ritual-ritual khusus seperti semedi untuk terus mengolah jiwa dan rasa batin.

Banyak upaya untuk mencapai tingkatan manunggal dengan Tuhan salah satunya adalah dengan cara memahami tiga tingkatan berikut seperti yang diungkapkan oleh Hadikoesoemo yakni heneng, hening, dan henong. Heneng atau meneng (diam) memiliki arti sebagai proses berhentinya nafsu-nafsu dunia. Nafsu-nafsu yang buruk dalam diri akan diolah melalui prosesi laku seperti puasa, tapa brata, pati geni, tapa lelana, dan lain-lain hingga menghasilkan kondisi yang disebut dengan diamnya nafsu atau lereming nafsu. $^{32}$ Setelah mencapai kondisi tersebut seseorang akan masuk ke kondisi hening atau bening, pada kondisi ini seseorang telah dirasa bersih pikiran dan jiwanya dari segala unsur yang bersifat materi dan hanya ada satu objek tujuan yakni

32 R.M. Soenandar Hadikoesoemo, Filsafat Ke Jawaan Ungkapan Lambang Ilmu Gaib Dalam Seni Budaya Peninggalan Leluhur Jaman Purba (Jakarta: Yudhagama Corporation, 1985), 143-144. Jurnal Intelektual: Jurnal Pendidikan dan Studi Keislaman Volume 10, Nomor 2, Agustus 2020
Tuhan. Kemudian tingkatan terakhir yakni henong atau kosong, pada kondisi ini manusia telah kosong dan siap menerima cahaya Tuhan. Pada tingkatan ini biasanya manusia telah memiliki kemampuan yang bisa membuka hijab dan mendapat petunjuk langsung dari Tuhan.

\section{Titik Temu Tasawuf dan Kebatinan}

Tasawuf dan kebatinan sebagai sebuah perjalanan mistik memiliki beberapa kesamaan yang pertama adalah secara tujuan yang hendak dicapai dalam kedua proses ini. Baik tasawuf atau kebatinan memiliki tujuan untuk mencapai derajat manusia yang sempurna yakni dengan pencapaian bersatunya makhluk dengan Tuhan-Nya. Konsep kebatinan manunggaling kawula gusti terasa lebih condong kepada model tasawuf falsafi yang keduanya memahami bahwa Tuhan dan manusia memiliki 'esensi' yang sama sehingga untuk mencapai kesempurnaan maka haruslah dapat menyatukan keduanya dalam artian bahwa manusia adalah ciptaan dan Allah adalah pencipta bukan menganggap bahwa manusia dan Tuhan berada dalam level yang sama.

Kesamaan selanjutnya adalah terdapatnya proses pelatihan jiwa untuk mencapai tujuan manusia yang sempurna, seperti yang diungkapkan oleh De Jong tentang distansi, konsentrasi, dan 
representasi. $^{33}$ Distansi berarti proses pengambilan jarak dengan dunia atau materi sebagai proses pengendalian nafsu karena dalam mistik rohani adalah inti manusia oleh karena itu jasmani harus dilemahkan. Seperti proses laku yang dikenal dalam kebatinan dan riyadhah yang terdapat dalam tasawuf seperti asketik, tapa brata, semedi, uzlah (nyepi, mengasingkan diri), zuhud (bersikap hidup sederhana), puasa, dhikr, tapa kelana (berkelana, berpindah dari satu tempat ke tempat lain), mengurangi dahar lan guling (makan dan tidur), pati geni dan lain sebagainya.

Kemudian konsentrasi, yakni sebuah kondisi di mana hanya ada Tuhan dan tidak ada yang dipikirkan selain Tuhan, peningkatan kearifan diri dan rasa batin sehingga tercapai kesatuan dengan Tuhan. Tahap yang terakhir adalah representatif yakni suatu tahapan di mana seseorang telah mampu mengidentifikasi Tuhan sehingga ia dapat bersatu dengan Tuhan (manunggal) dan kehidupanya sudah dipenuhi dengan sifat ilahiyah atau ketuhanan.

Kesamaan selanjutnya adalah dibutuhkanya guru atau pembimbing dalam proses laku atau riyadhah nya. Guru di sini berfungsi untuk mengajarkan tata cara atau tindakan yang harus dilakukan oleh seorang murid agar usaha dia mencapai derajat

${ }^{33}$ S. De Jong, Salah Satu Sikap Hidup Orang Jawa (Yogyakarta: Kanisius, 1976), 10-15. manusia sempurna berjalan dengan baik dan benar serta tidak malah terjerumus kepada kesesatan. Seorang guru haruslah telah mencapai derajat yang tinggi, sudah masuk dalam tahapan bersatu dengan Tuhan sehingga memiliki ilmu kasyaf atau terbukanya hijab-hijab dunia. Ia biasanya memiliki kemampuan supranatural atau kelebihan yang secara wajar dimiliki oleh orang yang telah mencapai tingkatan tertinggi. Aliran kebatinan menyebut guru mereka dengan guru kebatinan sedangkan dalam tasawuf seperti yang diungkapkan oleh Zaki disebut dengan syekh atau mursyid. ${ }^{34}$

\section{Kesimpulan}

Tasawuf dan kebatinan sebagai sebuah perjalanan mistik memiliki beberapa kesamaan yang pertama adalah secara tujuan yang hendak dicapai dalam kedua proses tersebut. Keduanya bertujuan untuk mencapai derajat manusia yang sempurna yakni dengan pencapaian bersatunya makhluk dengan Tuhan-Nya. Kesamaan selanjutnya adalah terdapatnya proses pelatihan jiwa untuk mencapai tujuan manusia yang sempurna. Selain itu, keduanya sama-sama mengindikasikan secara gamblang urgensi seorang pembimbing dalam melakukan proses mistik. Adapun perbedaan signifikan dari keduanya adalah

34 Muhammad Zaki, Tasawuf Hitam Putih (Solo: Tiga Serangkai, 2006), 194. 
tasawuf berasal dan bersumber dari ajaran Islam normatif, sedangkan kebatinan berasal dari kepercayaan dan budaya lokal masyarakat Jawa. Pada konteks Islam Indonesia keduanya mengalami akulturasi dalam aliran Islam kejawen atau yang lebih dikenal Islam corak Jawa.

\section{Daftar Pustaka}

Badrudin. Pengantar Ilmu Tasawuf. Serang: A-Empat, 2015.

Bakri, Syamsul. 'ISLAM KEJAWEN (Agama dalam Kesejarahan Kultur Lokal)." IAIN Surakarta. Last modified February 24, 2016. Accessed August 17, 2020. https:/iain-surakarta.ac.id/islamkejawen-agama-dalam-kesejarahankultur-lokal/.

De Jong, S. Salah Satu Sikap Hidup Orang Jawa. Yogyakarta: Kanisius, 1976.

Fadeli, Soeleiman. Antologi NU: Sejarah, Istilah-Amaliyah-Uswah. Surabaya: Khalista, 2007.

Hadikoesoemo, R.M. Soenandar. Filsafat Ke Jawaan Ungkapan Lambang Ilmu Gaib Dalam Seni Budaya Peninggalan Leluhur Jaman Purba. Jakarta: Yudhagama Corporation, 1985.

Hakiki, Kiki Muhamad. "Aliran Kebatinan Di Indonesia." Al-Adyan: Jurnal Studi Lintas Agama 6, no. 2 (December 31, 2011): 63-76.

Isa, Abdul Qadir. Hakekat Tasawuf. Jakarta: Qisthi Press, 2005.

Kartapradja, Kamil. Sejarah Klenik Dan Perkembangnya. Jakarta: Fakultas

Ushuluddin IAIN Syarif
Hidayatullah, 1972.

Koentjaraningrat. Kebudayaan Jawa. Jakarta: Balai Pustaka, 1984.

Madjid, Nurcholis. Islam Doktrin Dan Peradaban. Jakarta: Dian Rakyat, 2008.

Mulder, Niels. Kepribadian Jawa Dan Pembangunan Nasional. Yogyakarta: Gajah Mada University Press, 1973.

Nasution, Harun. Filsafat Dan Mistisisme. Jakarta: Bulan Bintang, 1978.

Said, Ridwan. Fiqh Klenik Fatwa-Fatwa Ulama Menyorot Tarekat Mistik. Kediri: Mitra Gayatri, 2004.

Schimmel, Annemarie. Dimensi Mistik Dalam Islam. Jakarta: Penerbit Pustaka Firdaus, 1986.

Shihab, Alwi. Antara Tasawuf Sunni Dan Tasawuf Falsafi Akar Tasawuf Di Indonesia. Depok: Pustaka Iman, 2009.

Sofwan, Ridin. Menguak Seluk Beluk Aliran Kebatinan (Kepercayaan Terhadap Tuhan Yang Maha Esa). Semarang: CV Aneka Ilmu, 2002.

Sosrosudigdo, Sawerdi. Fungsi Dan Aliran Kebatinan Untuk Pribadi Dan Revolusi. Jakarta: Balai Pustaka, 1965.

Sugiyono. Metode Penelitian Pendidikan (Pendekatan Kualitatif, Kuantitatif Dan $R \& D)$. Bandung: CV Alfabeta, 2010.

Sukmadinata, Nana Syaodih. Metode Penelitian Pendidikan. Bandung: Remaja Rosdakarya, 2010. 
Titik Temu Mistisisme Islam dan Mistisisme Jawa; Studi Analis is terhadap Ajaran Tasawuf dan Kejawen

Surakhmad, Winarno. Pengantar Penelitian Ilmiah Dasar, Metode Dan Teknik. Bandung: Transito, 1980.

Zahri, Mustafa. Kunci Memahami Ilmu Tasawuf. Surabaya: PT Bina Ilmu, 1979.

Zaki, Muhammad. Tasawuf Hitam Putih. Solo: Tiga Serangkai, 2006. 